\title{
Presence in Digital Spaces. A Phenomenological Concept of Presence in Mediatized Communication
}

\section{Gesa Lindemann ${ }^{1}$ (D) David Schünemann ${ }^{1}$}

Accepted: 27 October 2020 / Published online: 24 December 2020

(C) The Author(s) 2020

\begin{abstract}
Theories of face-to-face interaction employ a concept of spatial presence and view communication via digital technologies as an inferior version of interaction, often with pathological implications. Current studies of mediatized communication challenge this notion with empirical evidence of "telepresence", suggesting that users of such technologies experience their interactions as immediate. We argue that the phenomenological concepts of the lived body and mediated immediacy (Helmuth Plessner) combined with the concept of embodied space (Hermann Schmitz) can help overcome the pathologizing of digital communication in social theory and enable descriptions which are truer to the experience of using said technology. From this perspective it appears as an ethnocentric premise to restrict interaction to human actors being present in local space. This restricted understanding of interaction does not allow for an appropriate empirical analysis of the emerging structures of digital communication.
\end{abstract}

Keywords Digital communication · Embodied self · Interaction · Lived body · Helmuth Plessner $\cdot$ Phenomenology $\cdot$ Space $\cdot$ Social resonance space $\cdot$ Hermann Schmitz

\section{Introduction}

Sociological discourse about communication technologies often concentrates on phenomena deemed pathological, using terms such as "addiction" or "isolation" in reference to social media usage (e.g., Turkle 2011). In some ways, this reserved stance seems to be at odds with the enthusiasm with which modern society embraces such technologies; on the other hand, it echoes popular criticisms. Either way, the

Gesa Lindemann

gesa.lindemann@uni-oldenburg.de

David Schünemann

d.schuenemann@uni-oldenburg.de

1 Carl Von Ossietzky University, Oldenburg, Germany 
prevailing sociological perspective is characterized by an apparent indifference towards the actual experience of using such technology and by a demonization of its allure (Turkle 2011). Quite removed from this critical pretense, current empirical studies of digital communication technologies have discovered the phenomenon of "telepresence" (Bracken and Skalski 2010), "telecopresence" (Zhao 2015), or the phenomenon of "being together" without bodily proximity (Hardesty and Sheredos 2019). Ollinaho even argues that the "paramount reality of everyday life" (Schutz) has been "transformed to entail virtual realms" (Ollinaho 2018: 206). Similarly, Ayaß acknowledges that the online realm has become a normal part of our everyday life (Ayaß 2014). The focus of these studies is not on the pathological effects of such technologies, but rather on describing and even managing the actual experience of actors using them.

Such experiences are often dismissed as inferior to or less real than face-to-face interaction (see Sutter 2010; Turkle 2011). This assumption is based on a particular understanding of space going back to the implicit spatial concepts inherent in classical theories of face-to-face interaction.

Starting with a short overview of these spatial concepts, we show how they are unsettled by the empirical phenomenon of telepresence. As a consequence, we propose a phenomenological conception of space which defines mediatized communication as an interaction of lived bodies in a "social resonance space". We develop a heuristic for the analysis of the technical functions of digital communication media as they establish a social resonance space and show how this can be applied to the analysis of communication through e-mail in open source software communities. The aim is to come up with more accurate descriptions of the actual experience of using communication technologies and the accounts thereof. This is a theoretical paper, which also provides an empirical example to give a principle proof of the empirical fruitfulness of our proposed concepts.

\section{Mediatized Communication, Social Interaction and Space}

Analyses of "mediatized" (Krotz et al. 2014: 11) communication have compared it to face-to-face interaction since the early days of the internet (see Esposito 1995; Wehner 1997; Sutter and Charlton 2001; Sutter 2010). In these approaches, the sociological concept of face-to-face interaction is defined by people being in close spatial proximity to each other (Sutter 2010: 88). Thus communication between people who are not in the same place at the same time does not, in this view, count as interaction. Instead, auxiliary constructs such as "artificial communication" (Wehner 1997: 97), "artificial interactivity" (Mehler 2010) and "virtual intimacy" (Turkle 2011: 12) are developed to criticize mediatized communication and to differentiate it from "natural interactions" (Wehner 1997: 97), "real relations" (Sutter 2010: 95) or "a full social life" (Turkle 2011: 11). Mediatized communication is here placed in a "parallel universe", a cyberspace (Esposito 1995: 226). This idea corresponds to the sociological narrative according to which the spatial dimension is becoming 
increasingly less important for understanding sociation processes in modernity (Schroer 2006: 172).

However, in the past decade, theoretical studies have been published that focus on the importance of space for sociation processes (Schroer 2006; Löw 2016). This seems to contradict empirical research in the field of mediatized communication, which emphasizes the category of time rather than the category of space (KnorrCetina 2009; Werron 2015). At the same time, research is being done that highlights the importance of the experience of presence (Bracken and Skalski 2010; Hahn and Stempfhuber 2015; Zhao 2015) and the relevance of the embodiment of actors (Knorr-Cetina 2009). We argue that it is a contradiction to emphasize presence and embodiment while at the same time marginalizing space. These contradictions impose on us the urgent task of finding ways to conceptualize mediatized communication in relation to space. We develop our argument in three steps.

First, we elaborate the implicit concept of space employed in interaction theories and in studies of mediatized communication based on these theories. We show that this concept can be traced back to the concept of presence in a shared physical space in classical face-to-face interaction theory. It turns out that both Goffman and the studies that draw on his concept of face-to-face interaction employ an understanding of sensual perceptibility when they talk about presence, while Luhmann introduces a constructivist element in the sense that sensually perceptible actors can be treated as absent in social settings. We call this a 'halved constructivism' because it does not entertain the possibility that those who are, in a physical, perceptible sense, absent, can conceptually be present.

We then present a phenomenological concept of space that accounts for its various facets and introduce an expanded constructivism grounded in the theory of the lived body of Helmuth Plessner (1928/2019) and the concepts of space developed by Hermann Schmitz (1967). This concept of space allows for absentees to be treated as present and thus completes Luhmann's halved constructivism.

Finally, we show how this approach enables new insights into mediatized communication by way of an empirical example from the field of open source software development.

\section{Implicit Concepts of Space in Theories of Face-to-Face Interaction}

Luhmann's theory of communication media has been the starting point for analyses of mediatized communication, in particular with regard to interactivity and its relationship with the mass media system, for decades (Esposito 1995; Wehner 1997; Sutter and Charlton 2001; Sutter 2010; Schrape 2011; Dickel 2013). Goffman's concept of 'social situations' serves as a theoretical point of reference for other studies (Knorr-Cetina 2009; Rettie 2009; Licoppe/Morel 2016).

In both theoretical traditions (Luhmann and Goffman), mediatized communication is contrasted with face-to-face interaction. In both cases the interaction partners' presence in close proximity in a shared physical space is the foundation of face-to-face interaction. The notion of physical distance between humans is treated as an unquestioned basic assumption in social concepts of interaction. 
Goffman's (1981b: 84) definition of the social situation is based on a decidedly "physical" spatial conception where physical proximity is always thought of in connection with perception: "By a social situation I mean any physical area anywhere within which two or more persons find themselves in visual and aural range of one another". Goffman names two crucial characteristics of the face-toface situation that are also based on perception: "Richness of information flow and facilitation of feedback" (Goffman 1963: 17). The "richness" of the information flow refers to the multitude of channels of perception and the diversity of signals beyond language symbols. On the basis of this broad flow of information, Goffman presents a "biological" argument for the distinctiveness of face-to-face interaction: "Emotion, mood, cognition, bodily orientation, and muscular effort are intrinsically involved, introducing an inevitable biological element. Ease and uneasiness, unselfconsciousness and wariness are central" (Goffman 1983b: 3 ). According to Goffman's concept of the social situation, physical copresence poses existential risks: "We become vulnerable to physical assault, sexual molestation, kidnapping, robbery and obstruction of movement [...]. Similarly, in the presence of others we become vulnerable through their words and gesticulation to the penetration of our psychic preserves, and to the breaching of the expressive order we expect will be maintained in our presence" (Goffman 1983b: 4). To what extent the experience of vulnerability also arises in mediatized communication is not addressed in Goffman's field of research.

Goffman differentiates between "information given" and "expressions given off" and devotes most of his attention to the latter in his studies. The body as an expressive surface plays a prominent role in this conception. Glances, facial expressions and gestures, intonation, posture, and "surface decorations" (clothes and accessories) express more than is communicated via linguistic utterances and are compared to information communicated in language. Expressions given off are typically seen as more authentic and less controllable in social situations. This leads Goffman to conceptualize a fundamental asymmetry between speaker and audience: the audience presumes to be able to read expressive messages from the behavior of the speaker, which he himself cannot control (Goffman 1959: 7). Based on these distinctions, mediatized communication appears as a reduced form of communication: "Presumably the telephone and the mails provide reduced versions of the primordial real thing" (Goffman 1983b: 2).

Luhmann (1995: 413) adopts the concept of mutual perception for his systemstheoretical interaction concept, and, like Goffman, ascribes an ability to modalize communication through parallel processes of mitigation, amplification, or communication at a level of (intentional or unintentional) "indirect" communication, which makes it possible to avoid the high risk of explicit action.

Thus, when distinguishing between perception/expression and communication, the subtle nuances of "indirect" communication become the focus of analysis. This means that perception functions as a catalyst for attributing messages to the sender which he can be imputed to have communicated involuntarily.

Neither Luhmann nor Goffman considered the possibility that new communication technologies could have an impact on its users' perception of mutual perceptibleness. Empirical analyses of new forms of mediatized communication suggest, 
however, that mutual visibility and thus "indirect communication" can also occur here (Bracken and Skalski 2010). For both Goffman and Luhmann, by contrast, physical proximity is synonymous with mutual perception and related modes of communication.

Luhmann's descriptions of the pressure to accept communication offers in social situations (1995: 159f.) rely on an implicit phenomenological argument: the local proximity of alter ego's body impresses ego in a different way than a body that is far away from him. While this assertion is intuitively comprehensible, it is neither empirically nor theoretically substantiated in Luhmann's work. ${ }^{1}$ Similarly, physical space is an unquestioned premise of Goffman's "body-to-body starting point".

Both authors restrict the possibility of experiencing presence to actors who are physically close to each other. An embodied experience of presence (see Sect. 3 below) is not within the scope of classical definitions of social situations.

While Goffman explicitly refers to physical space, Luhmann's (2013: 134f.) conception contains a constructivist element. From this perspective, it is not space itself that is socially constructed, but rather "social" presence, by which Luhmann means that people in close proximity to each other can still be treated as if they were absent (see also Luhmann 2013: 133).

The strengths as well as the shortcomings of this concept become apparent in Kieserling's (1999: 15) studies of interaction systems, which expand on Luhmann's theory. Kieserling (1999: 64) also distinguishes between "physical presence" and "social presence" and notes that the boundaries of interaction systems are a result of neither physics nor consciousness, but rather of social construction (Kieserling 1999: 65). Like Luhmann, he considers the possibility of "being treated as absent", evoking the example of servants who can be treated as absent by their masters and their visitors even if they are in the same room (Kieserling 1999: 64f.). Just as in Luhmann, however, there is no indication of the possibility of treating people as "socially present" who are "physically absent". The possibility that communication technology might alter the experience of mutual perceptibleness is not taken into consideration.

This shows that, while social construction is stressed in theories of face-to-face interaction, space is at least partly conceptualized as a physical reality beyond the realm of social construction. In particular, classical interaction theory does not consider the possibility of actors experiencing presence through mediatized communication.

\section{Evidence of the Experience of Presence in Studies of Mediatized Communication}

As early as 1995, Elena Esposito suggested overcoming the one-sidedness of remote electronic communication (Esposito 1995: 226). Similarly, Wehner (1997: 96) discussed the possibility of conversation using digital communication devices

\footnotetext{
${ }^{1}$ His reference to socio-anthropological studies of primitive tribal cultures (Luhmann 2013: 151f.) is not very convincing. Ethnological studies do in fact show evidence of a space of vastness that can be experienced by the lived body (Leenhardt 1947/1979).
} 
despite the temporal and spatial separation between participants. Wehner (1997: 97) calls this a "simulated" variant of "natural interaction". He draws the boundary between simulation and nature by identifying the latter with a shared perceptual space in which the bodies of the participants are mutually visible and audible. Wehner (1997: 107) claims that the reflexiveness of perception, which he considers fundamental for interactive communication, is prevented by intermediate technology. Likewise, Sutter (2010: 88) argues that digital communication by definition cannot be understood as interaction. He cites two essential characteristics of interaction among present actors that he claims do not apply to mediatized communication: wide-ranging possibilities of expression (such as gestures, facial expressions, etc.) and immediate feedback. He concludes that mediatized communication is not a question of relations between people who perceive and identify themselves as persons, but rather of relationships between texts (Sutter 2010: 95).

Klemm and Staples (2015: 115) instead propose dropping the distinction between mediatized and non-mediatized and replacing it with that between physical and textual self-representation in interaction. They conceive of the body itself as an interaction medium (Klemm and Staples 2015: 121ff.). In contrast to the works of Esposito, Wehner, and Sutter, Klemm's and Staples' (2015) concept of interaction encompasses empirical phenomena in which media users experience any bidirectional communication as interaction.

The phenomenon of sensing presence in mediatized communication has been called "telepresence" or simply "presence" (see Bracken and Skalski 2010). Lombard and Ditton define "presence" in media usage as "the perceptual illusion of nonmediation [that] occurs when a person fails to perceive or acknowledge the existence of a medium in his/her communication environment and responds as he/ she would if the medium were not there" (Lombard and Ditton 1997). The authors consider "presence" to be a dependent variable and study factors which influence this "illusion" such as screen size and the quality of artificial 3D worlds. Westerman and Skalski (2010: 66) also acknowledge that "even simple computer cues like text communication can create the 'social presence' of a human". They argue that "social presence" is becoming increasingly important in today's media use (Westermann/Skalski 2010: 138).

Licoppe (2004: 135) observes that today, face-to-face and mediatized communication seamlessly blend into each other in everyday life: "The (physically) absent party gains presence through the multiplication of mediated communication gestures on both sides, up to the point where copresent interactions and mediated distant exchanges seem woven into a single, seamless web". Licoppe (2004: 139) does not deal explicitly with conceptualizations of spatiality but observes an inhibition threshold to recognize "strong ties" formed over the Internet: "The liveliness of these debates is [...] a symptom of the difficulty of conceiving of the establishment of strong ties without moments of physical copresence". Licoppe's studies show that the clear distinction between "cyberspace" and the "real world" is no longer an appropriate way to describe how his subjects experience using communication technology. In line with Licoppe's findings of a "seamless web," van Doorn finds that "online articulations of gender, sexuality and embodiment 
are intricately interwoven with people's physical embeddings in everyday life" (van Doorn 2011: 532).

In a similar vein, Karin Knorr-Cetina (2009: 65) puts forward the concept of "synthetic situations," which she uses to extend the interaction concept to computermediated communication: "On a global scale a 'situation' invariably includes, and may in fact be entirely constituted by, on-screen projections - it becomes a synthetic situation". Knorr-Cetina also finds clear evidence of the importance of the body for synthetic situations: "Global situations tend to be [...] centered on forms of embodiment" (2009: 62). In her studies of exchange traders who spend their working day in front of screens, she notes: "Their bodies and the screen world melt together" (2009: 64f.). This "merging" of body and screen breaks the clear separation between the physical environment and the world on the screen. Stock market traders are also physically affected by the activities of other traders: "Though traders are not able to slip through the screen and walk into the 'life form' of the market, they stand within its intimate space-close enough to feel every 'tick' of its movements, and to tremble and shake whenever it trembles and shakes" (Knorr-Cetina 2009: 75). The colorful language with which her research subjects describe their interaction with other traders-e.g., "The guy stuffed me" (Knorr-Cetina 2009: 75)—clearly points to the physical dimension of "synthetic situations". There seems to be little grounds for describing these encounters as "disembodied" (Ullrich and Schiek 2015: 134).

These findings imply a rupture with conventional "physical" concepts of presence and spatiality. Knorr-Cetina (2009: 74) uses Goffman's concept of "response presence" in order to try to grasp this shift in spatial references: "I define response presence to mean that the interacting party is not or need not be physically present but is accountable for responding without inappropriate delay to an incoming attention or interaction request". Presence in this field is therefore not constituted by the physical presence of bodies, but by the expectation of responses. Finally, Knorr-Cetina (2009: 79) even eliminates space from her definition of synthetic situations: "The interacting partners meet in time rather than in a place". In this way, Knorr-Cetina participates in the sociological narrative of space becoming displaced in modernity. Zhao argues likewise that telecopresence allows people to "share a community of time without sharing a community of physical space" (Zhao 2015: 114).

We have shown that both Luhmann's systems theory and Goffman's interaction theory use similar concepts of presence, which foreground the presence of bodies in a particular place. The problems this gives rise to in the analysis of digital interaction lead some authors to extend the definition of presence. The terms "telepresence" (Lombard and Ditton 1997), "connected presence" (Licoppe 2004) and "response presence" (Knorr-Cetina 2009) point to an embodied experience of presence. However, the attempt to conceptually grasp the empirical findings leads to ambivalent results, especially in the case of Knorr-Cetina. She displaces the spatial aspect in favor of a purely temporal conceptualization of presence, while at the same time emphasizing embodiment. But to include the body outside of the spatial dimension seems to be contradictory. Lombard and Ditton avoid this narrow focus on synchronicity and concentrate on the experience of technology users.

Phenomenological approaches seem to go a step further. According to Hahn/ Stempfhuber (2015: 123), presence can be experienced through technologically 
mediated signals that generate immediate response expectations. This indicates a preference for time, which is likewise present in the work of Zhao (2015), Ollinaho (2018), and Hardesty/Sheredos (2019). These studies follow Schütz's analysis of the life-world (Schütz and Luckmann 1973), which at first sight seems to incorporate space and time in equal measure. Schütz starts with an analysis of the actor's experience of the here and now, focusing on the practical accessibility of things in the lifeworld and on how we interact with others in close proximity.

At least implicitly, Schütz' approach does however lead to a preference of time over space, as Srubar notes. "It is clear that public time is the dimension in which different perspectives can come up against each other: public, because a supra-individual dimension is required; time (and not space), because the world is perceived in an egocentric way, i.e., the respective 'hic' and 'illic,' that is, the spatial standpoint, determines perspective along with the particular biographical situation" (Srubar 1979: 47) Srubar's work shows that time is the supra-individual dimension, making it crucial for sociological analysis. Thus the studies following Schütz also display a preference for time.

Hardesty and Sheredos 'take Schütz's account of the spheres of social reality as they occur in the everyday life-world and apply it to parallel spheres of social reality that arise in the virtual worlds of multiplayer online games" (Hardesty/Sheredos 2019). According to Hardesty and Sheredos, we can drop the assumption "that everyday spatial proximity is required for face-to-face* interactions " (2019: 368, see also: 369). Zhao argues that in telecopresence "individuals are physically remote from one another, hence 'tele'; but in the sense that they are able to reach one another in real or near-real time through electronic mediation, the individuals are temporally together with one another, hence "copresence", (Zhao 2015: 115). Ollinaho's (2018) analysis of "the virtualiziation of the lifeworld" focuses on how the paramount reality of everyday life has itself been transformed and now also entails virtual worlds. Our active attention is demanded not only by the paramount reality of everyday life in Schütz's sense, but also by virtual worlds (Ollinaho 2018: 206f). Ollinaho's analysis is more about how we organize our attention-the spatial structure of our experience is not a crucial topic in his work.

Klemm and Staples (2015) also draw on phenomenological considerations and cite Gugutzer (2012), who seeks to introduce Schmitz's phenomenology of the lived body into sociology. Similarly, Gardner and Jenkins (2015) analyze experiences of digital technologies on a phenomenological basis and find that participants in their experiments react in "varied, embodied ways, translating the data representations into more complex narratives inspired by their embodied experiences" (Gardner and Jenkins 2015: 24.). In his analysis of video-conferences, Friesen (2014) centers on the "intentionally structured experience of space, time, body and relation" (Friesen 2014: 20), but does not unfold a differentiated concept of space. Instead, following Merleau-Ponty and Waldenfels, he focuses on the ambiguity of presence and absence in the experience of embodied interactions and in tele-mediated encounters. (Friesen 2014: 28).

In summary, we can state that, according to the phenomenological tradition, the immediate embodied experience can be included in the analysis. Nevertheless, in the tradition of Schütz, this leads to focusing on temporality while neglecting the 
spaciality of exerience. Although, following Merleau-Ponty and Waldenfels, the meaning of space can be included in the analysis to some extent, it remains impossible to grasp the spatiality of experience in a differentiated way with the concepts put forward by these authors. We would like to extend these efforts with a proposal that integrates the spatiality of the social into a concept of embodied presence. This allows us to explicate the implicit phenomenological borrowings in Luhmann's and Goffman's concepts.

To this end we take up Helmuth Plessner's (1928/2019) philosophical anthropology $^{2}$ and Hermann Schmitz's phenomenology of space.

\section{Embodied Space}

Our aim in incorporating the perspective of the lived body is to complement and render more precise the concepts put forward within the more recent sociology of space, which is a part of the more general "spatial turn" (Bachmann-Medick 2016). Space is understood as being constructed by "social operations" such as "spacing" and "operation of synthesis" (Löw 2016: 134ff.). However, it remains uncertain here whether and, in particular, how actors carrying out these social operations are themselves spatially constituted in their references to their environment. ${ }^{3}$

The proposals put forward by Helmuth Plessner and Hermann Schmitz seem more productive to us here. Their concepts also allow us to address the confusion surrounding the problem of presence in Internet-mediated communication. Following Plessner's (1928/2019) theory of excentric positionality, we understand the relationship of embodied selves to their environment as a mediated immediate relationship. The concept of mediated immediacy allows us to take into account both technical as well as socio-symbolic mediations of lived body-environment relationships (see Plessner 1928/2019; Lindemann 2020: 107ff., 165ff., 185ff.).

The "body-to-body starting point" of interaction theory is made more precise by distinguishing between the lived body [Leib] and the physical body [Körper]. This means that instead of thinking in terms of bodies perceiving the world, we think in terms of embodied selves experiencing it. With this move, physical space as the definitive boundary of the reach of the social situation ceases to be self-evident, and space as experienced by lived bodies can be broken down into different "modes of spatial givenness" (Schmitz 1967: chap. 2) for the embodied self. These modes

\footnotetext{
${ }^{2}$ The works of Plessner and Schmitz are less well known in the English speaking world. At present this changes at least for Plessner. His major work ,The levels of organic life and the human “ has been published in summer 2019. See also the Special Issue of "Human Studies. A Journal for Philosophy and the Social Sciences" (Vol. 42:1, 2019) on "Helmuth Plessner 's Philososphical Anthropology. Its significance for a Philosophy of the Living and the Analysis of Societal and Cultural Orders".

3 This becomes obvious in Berger's study (2020), which refers not only to phenomenological sociology but also to the theories of Löw. Berger argues that "actors synthesize a single hybrid space, in which the virtual space (constituted under circumstances of virtual presence in the game's finite province of meaning) and the space of the body and its physical surroundings are linked to each other" (Berger 2020: 14) It is a crucial insight that space is dependent on the operations of spacing and synthesis, but it remains an open question how actors themselves exist as spatial beings.
} 
can be differentiated in empirical observation. Thus, for instance, the question of whether something is a "full" interaction can be separated from the observation of the distances between the bodies in question and located in the experiences of the selves. Distance and proximity are then no longer regarded as objectively measurable quantities which determine whether deviating statements in the field appear as illusion or syndrome, but are rather conceptualized as descriptions of embodied actual experience. Making this experience into the object of empirical observation allows for the possibility that mediatized communication can be experienced as a social situation.

In his phenomenological archeology of space, Schmitz distinguishes between three different forms of space: (1) the unstructured space of vastness [ungegliederter Weiteraum], (2) embodied directional space [leiblicher Richtungsraum], and (3) local space [Ortsraum]. We suggest adding a fourth form to this list: digital space, that is, space measured in arbitrarily small units. Overall, this understanding of space allows us to conceptualize the particularities of the presence of others as well as to understand the technical characteristics of the space of digital communication. In the following, we give a brief overview of the lived body-environment relationship, the forms of space, and the relationship between space and sociality, in order to then formulate a hypothesis about the changes initiated by new media that takes up our criticism of the approaches summarized above.

\section{Lived Body, Environment, and the Forms of Space}

Conceiving of action, interaction, and communication from the perspective of a theory of the lived body means to understand social actors as embodied selves (for the following, see Plessner 1928/2019):

1. An embodied self experiences itself here/now in relation to its environment.

2. It perceives its environment and anticipates a future with concrete relevance for the current situation. This future is embedded in a broader future horizon.

3. The embodied self is less a subject perceiving its situation from a distance and more a self experiencing itself here/now as affected by the events in its surroundings.

4. At the same time, the self mediates between its perception of its surroundings, its experience of its own condition, and the expected future by relating its behavior and actions to its environment.

5. Excentric embodied selves do not exist in a purely immediate embodied way in relation to their environment; their relationship to it and to themselves is rather mediated by technology and symbolic-institutional structures.

Starting from the lived body means analyzing sociation as a situated, spatiotemporally structured execution of embodied relationships to the environment. It is not about individual actors acting and making decisions, but about how these actors are technologically and symbolically mediated and integrated into their situation, how 
they are affected by it, and how they act and impact on their environment and communicate with others accordingly.

Understanding the relationships between lived bodies and their environment in this way allows us to characterize the forms of spatial experience referred to above as follows. The unstructured space of vastness can be illustrated by the experience of lying in the sun, squinting into the sky without fixing your gaze on anything in particular. It is possible within the context of such an experience to forget entirely where you are. Nevertheless, you experience yourself here/now as extended, pleasantly warm, and surrounded by a gentle current of air. Individual places cannot be made out in this relationship to the surrounding space. A similar experience of space can be had in the dark, listening to the surrounding stillness with your attention focusing 360 degrees, as it were. There is a surrounding space, but you do not direct yourself into it in a specific way and no specific places become distinguished in it. Phenomenological analysis shows that this unstructured vastness surrounding the lived body existing here/now is the fundamental way in which embodied actors relate to space (on the space of vastness overall, see Schmitz 1967: 47ff.).

Directional space must be distinguished from the unstructured space of vastness (see Schmitz 1967: 54ff.). It is also characterized by a relationship to the here/now, which here, however, forms a center from which directions emanate right/left, above/ below, or in front of/behind. Characteristic of embodied directional space are action centers that direct themselves into their environment. For example: An embodied self glances to the left at a book, then at an another embodied self, then back at the book with a pointing gesture and says, "Look, there it is". This kind of spatial orientation two embodied selves presupposes a shared space (space of vastness) into which both of them can direct themselves. This unstructured space is given direction by embodied action centers as they act. As a result, pathways of habitual self-direction emerge, that is, pathways of perception, of taking hold of things, or of walking important for everyday functioning. ${ }^{4}$ Experiential and active executions of embodied relationships to the environment make it possible for embodied selves to touch each other-by means of glances and gestures and, in a symbolically mediated way, also by words.

In distinction to directional space, local space is structured by relationships of position and distance (Schmitz 1967: 72ff.). In local space, a single point would be completely undetermined; it becomes positionally defined only in relation to other points or lines. Three-dimensionally extended bodies are constantly setting themselves apart in local space. They are located at a particular time in a particular place in space, that is, in a position that can be precisely calculated by means of relationships of position and distance with other bodies (Schmitz 1967: 54). In order to know where a body is, I have to locate it relative to other bodies. Furthermore, since bodies can be moved around in space, the space that a body just occupied can be distinguished from the body itself. A local space is a space that may or may not be occupied by bodies.

\footnotetext{
4 The aspect of directing oneself at something in one's environment is also theorized by Merleau-Ponty (1945/2014: 100ff.). For an analysis of the difference between Plessner's and Merleau-Ponty's understanding of the lived body see Lindemann (2010).
} 
Local space as well as the bodies occupying it can be described as measurably extended, which means that local space as a whole can be described as a measurable extension that can be broken down into arbitrarily small units, each of which are continuously connected to each other. If this space is fully mathematized and without any connection to embodied spatial experience, it is a digital space. All references to local space as accessible by the lived body have been erased here. It was not until the transition to modernity that the digitization of local space became completely established. ${ }^{5}$ Digital space forms the basis for the development of modern control and communication technologies (Lindemann 2020: 176ff.).

\section{Space and Sociality}

The embodied giving direction of the space of vastness and the situating of embodied action centers in a structured local space can be taken to ground, from the perspective of a phenomenology of the lived body, what Löw describes as "spacing" and "operations of synthesis". It is here that the spatiality of embodied actors' relationship to their environment becomes observable as such.

In our phenomenological approach, we comprehend space not only in terms of its attachment to the "here" of the standpoint, but also as a relationship to surrounding space. The structuring of spatial forms that follows from this allows for an understanding of space as also enabling sociality. There are different possibilities here. Goffman's and Luhmann's concepts of space based on interaction, presented in Sect. 2, above, implicitly operate with a concept of local space when analyzing the relationship between sociality and space. Spatial proximity is seen as the condition for overcoming the separateness of spatial standpoints, and interaction takes place between those bodies that are present in a particular place. The minimum requirement for someone to be present (Goffman's concept of space) or to be treated as present (Luhmann's constructivist concept of space) is to be visible and within earshot or calling distance. This ties presence-or, in the case of the constructivist concept of presence, the possibility of being treated as present-to immediate sensory presence.

Working with a phenomenologically differentiated concept of space-i.e., including the space of vastness experienced by the lived body as well as embodied directional space-opens up other ways of understanding the connection between space and sociality. Embodied actors experience a surrounding, unstructured space of vastness and direct themselves into it. This makes the surrounding space of vastness into a potentially social space (Lindemann 2020: 127f.) or into a "social space of resonance" (Fritz-Hoffmann 2017). ${ }^{6}$ Embodied actors direct themselves into

\footnotetext{
5 Panofsky (1927/1991) was one of the first to describe what is historically new about digital space: the possibility of calculating space mathematicallyspace.

6 Our understanding of resonance space is different from the concept of resonance employed by, e.g., Hartmut Rosa (2016/2019), who analyzes the loss of resonance as alienation. We make use of the concept in a purely descriptive way to refer to the phenomenon of touching/affecting, or being touched/ affected, by others. Whether this touch is experienced as pleasant or terrifying or whether it takes place within an alienated relationship is insignificant.
} 
the surrounding space using, for instance, glances and gestures, thereby touching/ affecting other embodied selves. This possibility is one of the-generally tacitbackground expectations of embodied selves. Thus one can feel a glance without immediately being able to identify where it's coming from. In other words, without being able to tell right away where the body is located from which the glance is coming from, a perceiving embodied self senses that someone is looking at it. Similarly, sounds can also be experienced as an indication of the immediate presence of another even if it is not possible to determine where that other is. Every rustling or scuffling noise can indicate the immediately experienced presence of another. The studies on the phenomenon of presence presented above (Bracken and Skalski 2010; Licoppe 2004) suggest that in addition to glances and sounds, mediatized gestures of communication, such as for instance "textual self-representations", can also be experienced as indications of presence.

The surrounding space of vastness is not structured according to places or measurements and distances; it is unstructured space. At the same time, actors expect others to be able to direct themselves at them from out of this space, making it into a social resonance space. Social resonance space is the surrounding space of vastness insofar as actors expect to be communicatively addressed from out of this space. If we expect to be communicatively addressed from out of the surrounding space of vastness, we have entered into a social resonance space.

Our analyses in the following are anchored in these phenomenological concepts of embodied selves and space.

\section{Mediated Immediacy}

Integrating the differentiated phenomenology of spatial forms following Schmitz with Plessner's concept of "mediated immediacy" (Plessner 1928/2019: 324f.) leads to further analytical perspectives (see Lindemann 2020). Mediated immediacy means that a phenomenon is technically or symbolically mediated but is nevertheless experienced as immediate; technically mediated immediacy is understood to be a continuation of the mediatedness of the physical/lived body's experience of its environment. Plessner develops his concept of the lived body starting from the objectified body. ${ }^{7}$ The objectified body refers to the three-dimensionally extended body located in a particular place in local space. By contrast, the lived body refers to a living body that has itself as the means of its relationship to its environment. Thus for the objectified body, seeing, for example, is a process in which light stimuli encounter bodily sensors, which process and transmit them as neural signals. At the same time, the seen phenomenon is perceived as immediately present in surrounding space. In the experience of this perception, the bodily mediation is dominated by the immediacy of the lived body's relationship to its environment. Embodied experience of the environment thus means an immediate sensory experience of the environment. The notion of mediated immediacy describes this concurrence of immediate

\footnotetext{
7 On the distinction between physical body [Körper] and lived body [Leib], see Lindemann (2010).
} 
embodied experience and bodily-organic mediatedness. As means, the body has the character of an "apparatus" and, as lived body, is at the same time the subject of its life (Plessner 1928/2019: 186). As apparatus, the mediating organs can be at least partially replaced, optimized, or augmented. Phenomena that are made accessible by technically augmenting perception can also be experienced as immediately given in line with Plessner's principle of mediated immediacy. In the following, this assumption guides our analysis of the digitally/technically mediated perception of the immediate presence of other actors.

The use of language and writing points to the symbolic mediatedness of the presence of others. ${ }^{8}$ A linguistic utterance describing a state of affairs leads it to be experienced as immediately given. Social relationships are technically/symbolically mediated in manifold ways and at the same time are experienced as immediate social relationships.

\section{The Empirical Significance of the Concepts of the Lived Body and of Embodied Space}

Building on the concepts of embodied space, local space, and technically mediated, predimensional, social resonance space, we will now seek to identify one of the historical changes in spatial experience that is expressed in mediatized communication. As a starting point we can identify a type of spatial experience that is determined by the interconnection between local space and embodied directional space and distinguish it from a recently emerging structure of spatial experience that is characterized by the interconnection between an embodied relationship to space and the unstructured space of vastness, which is at the same time a (in part) technically mediated social resonance space.

The interconnection between embodied directional space and local space can be illustrated by the example of getting one's bearings with a city map. The creation of a city map presupposes a measured, three-dimensionally extended space, which allows for a controlled translation of territory to map. When an embodied actor reads the map, she positions herself on this map and then orients herself with her lived body: I'm standing here; I need to turn left at the third intersection, then right, then another left; then I'll look at the map again. Objectified local space and the form of embodied orientation become interconnected in this process in a way that seems to characterize embodied actors' relationship to space in modern societies. Furthermore, according to both Goffman's and Luhmann's implicit concept of space, local space is the epitome of social space. Thus the interconnection between embodied directional space and local space also implies that the primary sociality of embodied actors is tied to local space. Accordingly, sociality in this view is primarily understood as interaction between actors present in local space. Other forms of communication are seen as having to simulate the ordering functions valid in the

\footnotetext{
8 This aspect was emphasized in the "linguistic turn" in the social sciences; see Habermas (2003). For an integration of the insights of the linguistic turn with the concept of mediated immediacy, see Lindemann (2020: 185ff.).
} 
interaction between locally present actors or having to replace them with other functions. Luhmann's media theory is a good example of this approach. Schütz's theory of the lifeworld similarly ties the primary sociality of embodied actors to local space.

We propose changing the premise: instead of starting from the interaction between actors present in local space, we suggest foregrounding the state of affairs of embodied actors directing themselves into a surrounding space of vastness who are able to touch/affect each other, or are able to experience being touched/affected, either in a directly embodied, or in a technically and symbolically mediated way. In our view, limiting the definition of interaction to actors present in local space is based on a historically contingent state of affairs. In ethnological research (see Leenhardt 1947/1979: chap. 4, 5), for one, there are numerous examples of interactions with actors (such as ghosts or deceased ancestors) that cannot meaningfully be situated in three-dimensionally extended local space, but can indeed be situated in an experiential space without a local-space structure. Our assumption is that mediatized communication in some senses exhibits similar structures. Here too, the other actors are experienced as existing in unstructured, i.e., non-measurably extended space. They are experienced as being present somewhere in the surrounding space without being situated in a measurably extended place.

The surrounding space of vastness is only unstructured, however, in the sense that it is not structured according to measurably extended places. But it can be structured directionally or be experienced as socially/symbolically structured. The big difference between space as described in the ethnological research (Leenhardt 1947/1979) and the space of Internet communication is that the latter is technically mediated in a highly complex way. The modern social resonance space is based on a material technology whose mode of functioning requires a "digital space" completely detached from embodied experience. ${ }^{9}$

As set out above, the definition of interaction among locally present actors in Luhmann and Goffman is based on two-in the case of Luhmann three-key assumptions: first, space is understood only as local space in the sense of Schmitz that is there is a shared, physically conceptualized perceptual space in which the bodies of those involved can hear, see, and touch each other - the space of vastness and the embodied directional space is not taken into account; second, turn-taking allows for the possibility of "feedback" (see Goffman 1963: 17 and Sutter 2010); third, for Luhmann presence includes being forcibly coerced to accept proposals of meaning. As discussed above, the empirical studies following these two respectively three assumptions deny that mediatized communication have the character of interaction since it allegedly lacks a reciprocal perceptual space. According to these premises interaction is restricted to human actors being present in local space. This seems to be an ethnocentric premise (see also Luckmann 1970: 82). Referring to

\footnotetext{
9 Digital space differs from local space tied to the lived body in that the former only contains measurable relationships of position and distance and measurable physical conditions of bodies. Panofsky (1927/1991) was one of the first to describe what is historically new about this space, which makes it possible to mathematically calculate linear perspective and forms the basis for the development of modern control and communication technologies (Lindemann 2020: 176ff.).
} 
this understanding of interaction, it is neither possible to analyze interactions discovered in ethnographic research nor to analyze the emerging structures of digital communication.

A perspective that includes a theory of the lived body, by contrast, replaces the concept of perceptual space with that of space experienced by the lived body, which includes the space of vastness and embodied directional space. The embodied sensation of the presence of others is not limited in this conception to proximity in local space. An example from the field of open-source software development illustrates the advantage of this conceptual adjustment.

\section{On the Internet, Nobody can hear you Being Subtle}

In this section we use a concrete example to show in detail how the concepts of embodied selves, embodied space, and technically mediated, predimensional, social resonance space can inform an empirical analysis. So far, the social sciences primarily treat open-source software development as a novel production model, analyzing the organizational and positional structures at work in the projects undertaken. In the following, we focus instead on the spatial experience and the mediatization of communication in this context. In open-source projects, most of the communication takes place on the Internet, using a variety of services. In the development of the Linux kernel, for instance, mailing lists are an essential tool for the communication between developers scattered across the globe in different time zones. An empirical examination of this form of mediatized communication shows that the experience of presence in a shared social resonance space significantly contributes to the formation of structure in the field. Differentiating space according to a phenomenology of the lived body as proposed above provides helpful tools for describing these states of affairs.

The Linux kernel mailing list (LKML) is a public mailing list whose communication is archived on different websites, making it available for analysis by social scientists. Due to the popularity of the Linux project, the list is read by software developers, technology journalists, and interested lay people around the world. In 2013, a dispute between Linus Torvalds, the "benevolent dictator" of the Linux project, and a developer who had complained about Torvalds's leadership and communication style on the mailing lists caused a stir. The dispute lends itself well to describing spatial lived-body relationships in mediatized communication.

The discussion took place in 132 e-mails (approx. 60,000 words) on the Linux kernel mailing list ${ }^{10}$ between July 11 and July 24, 2013. For our analysis, we copied the e-mails from the mailing list archive site www.marc.info into a text file and coded them using MaxQDA. Participants in the discussion generally posted under their real names, with pseudonyms being an exception. ${ }^{11}$

\footnotetext{
10 The raw data is available at https://marc.info/? $\mathrm{t}=137358044500010 \& \mathrm{r}=5 \& \mathrm{w}=2$, retrieved December 292018.

11 The events examined here have already been made public in media reports (e.g., https://www.wired .co.uk/article/sarah-sharp, retrieved December 29 2018). Due to the public accessibility of the data in the mailing list archives and the relative prominence of the participants as a result of media coverage of the Linux kernel development, we have chosen for the most part not to anonymize the data.
} 
The media characteristics of the communication medium employed are explicitly reflected upon in the debate. The developers discuss the differences between communicating in this medium and communicating with locally present actors by calling on their own experiences and debating possible functionally equivalent solutions for transferring guarantees of successful interaction between locally present actors to communication on mailing lists. In particular, participants' descriptions of being affected in their lived bodies by their interactions on mailing lists takes on great significance in the controversy. While psychological or emotional vulnerability in mailing list communication is a contested notion in the discussion, at least some of the participants cite it as a relevant factor to consider when developing interaction orders.

The debate about communication styles on the mailing list begins with an e-mail by a kernel developer, quoted here in part:

$\begin{array}{ll}2508 & \text { [...] Linus Torvalds is advocating for physical intimidation and violence } \\ 2509 & \text { Ingo Molnar and Linus are advocating for verbal abuse } \\ 2510 & \text { Not *fucking* cool. Violence, whether it be physical intimidation, } \\ 2511 & \text { verbal threats or verbal abuse is not acceptable. Keep it professional } \\ 2512 & \text { on the mailing lists.[...] }\end{array}$

In this excerpt, written messages on the list are described by the developer as "abuse" and overall as "violence". From the perspective of a phenomenology of the lived body, these statements can be understood as documents of embodied experience. The developer describes herself as strongly affected in a negative way.

The following lines describe how the social resonance space is constructed by enacting particular interaction rituals. Torvalds at first responds evasively to the severe accusations:

\begin{tabular}{ll}
2538 & That's the spirit \\
2539 & Greg has taught you well. You have controlled your fear. Now, release \\
2540 & your anger. Only your hatred can destroy me \\
2541 & Come to the dark side, Sarah. ${ }^{12}$ We have cookies \\
\hline
\end{tabular}

We can identify different layers of symbolic mediation. Torvalds is quoting freely here from a science fiction film (Star Wars: Return of the Jedi, 1983), abandoning the level of "serious" kernel discussions. By code-switching (being ironic), he temporarily averts the confrontation. Torvalds initially avoids directly responding to the confrontation by changing his footing in the conversation, to use Goffman's term (see Goffman 1981a: 128). Using heavy irony, he places himself in the position of the evil Emperor intending to lure Sharp to the "dark side" with cookies (2538-2541). Deflecting from the issue at hand in this way can be read as a ritual

\footnotetext{
12 The developer, Sarah Sharp, has since taken on the first name Sage, identifying as non-binary and using the pronouns "they" and "them".
} 
that allows the other person in the discussion to "save face" (see Goffman 1967). At the same time, Torvalds lays claim to a position of power by initiating the codeswitch, adopting the role of "Emperor", and pushing his conversation partner into the role of apprentice.

Initially, Sharp goes along with this and there is a brief interlude:

$\begin{array}{ll}2715 & >>\text { But, but, the light side has brownies. Pot brownies that will make } \\ 2716 & >>\text { everyone feel sleepy and peaceful and possibly hungry. For more pot } \\ 2717 & >>\text { brownies... }\end{array}$

Sharp here plays the role of meek defender of the "light side" (2715-2717). They give expression to their intimidation by the sinister Emperor Torvalds (to keep with the metaphor) by pretending to stutter-by repeating "but" at the beginning of the sentence-and by the ellipses at the end of the paragraph. The scene is reminiscent of Goffman's “young American middle-class girl playing dumb for the benefit of her boy friend" (Goffman 1959: 74). Sharp is here validating Torvalds's claim to power and allowing him to save face himself, instead of, for instance, immediately rejecting his code-switch.

Typical interaction rituals can be identified in this passage. Participants use them to show each other respect and give each other the chance to save face. This structure contradicts Torvalds's superficially displayed contempt for these very interaction rituals. Later on in the discussion, he explains his frequently confrontational communication style, entailing the use of extreme swear words and personal insults, with a field-internal theory about mediatized communication on mailing lists:

2753 The fact is, people need to know what my position on things are. And I
2754
2755
2756

The quote in line 2755 is an allusion to the tagline of the science-fiction horror film Alien from 1979 ("In space, no one can hear you scream"), which Torvalds uses to point to the absence of prosodic elements in online communication. The tagline, used in marketing the film, alludes to the fact that empty space does not conduct sound waves, giving a foretaste of the spine-chiller's nightmarish atmosphere. Torvalds references the film in order to draw a parallel between soundless space and "soundless" online communication. Subtle variations of intonation and nonlinguistic sounds such as ironic grunting, a taunting voice, and mock anger (Goffman 1983a: 31) cannot be transmitted on mailing lists by way of voice modulation. Torvalds invokes the "soundlessness" of the social resonance space of mailing list communication in order to justify the way he expresses himself. The absence of prosodic elements, he suggests, makes it more difficult to extract from the e-mails the information the writer wants to communicate. He portrays swear words and insults as functional equivalents of prosody that can be used to give emphasis to a rejection or to accentuate a statement. 
Torvalds argues for a communication style that operates without the circuitous route of politeness and is occasionally spiked with swear words in order to unequivocally and clearly communicate rejection. He expresses his refusal to be considerate of emotions and culturally conditioned sensibilities and justifies this by pointing to the media characteristics of the communication technology being used. Torvalds refers to this strategy as "management by perkele". Perkele is a Finnish expletive that roughly translates as "devil". With his communication style, Torvalds, to speak with Goffman, wants to keep the recipients of his e-mails from looking "for an indirectly expressed intent, namely, that the speaker is being unserious (Goffman 1983a: 26). This line of argument is supported by other participants in the discussion. There is some speculation, though, that Torvalds's rough style could be "intimidating" to developers potentially interested in coming on board.

$\begin{array}{ll}3895 & \text { If the conversation weren't so public it may not seem } \\ 3896 & \text { as inappropriate. The shaming and flaming style is } \\ 3897 & \text { effective for keeping top people in line. But it does } \\ 3898 & \text { needlessly intimidate new people in the process }\end{array}$

This post connects the debate to the reproduction of the Linux project. The idea is that intimidation can become a problem if it leads to the failure to recruit new developers for the kernel development. At several points in the discussion, Torvalds is referred to, even by top developers, as "intimidating" and "scary". Being the victim of his "scolding" is described as an unpleasant experience. Public humiliation is also brought up several times in the developers' description of their embodied experience.

In view of all this, participation in the LKML can be described in terms of a social resonance space that can be entered or exited. On the one hand, statements are made that can be interpreted to mean that developers find the "atmosphere" on the LKML pleasant, such as the assertion that the shouting matches take place in a space populated by friends (line 3893: "the shouting is among friends, who care a lot"). This means that participating in the communication on the LKML generates the feeling of safety associated not with a particular place, but with a feeling of the presence of friends in the space of vastness of a social resonance space. The spatial dimensions of this experience are made explicit in a personal blog entry by Sharp, albeit with a distinctly negative tone:

Given the choice, I would never send another patch, bug report, or suggestion to a Linux kernel mailing list again. My personal boxes have oopsed with recent kernels, and I ignore it. My current work on userspace graphics enabling may require me to send an occasional quirks kernel patch, but I know I will spend at least a day dreading the potential toxic backgroung radiation of interacting with the kernel community before I send anything.

Source: https://sarah.thesharps.us/2015/10/05/closing-a-door/, retrieved December 292018 . 
The developer describes the LKML here as a space that gives rise in them to a feeling of oppressive fear. The metaphor of "toxic background radiation" turns the unarticulated space of vastness into an articulated space (see Schmitz 1967: 136 f.). The allusion to the phenomenon of toxic radiation evokes the association of an odorless, invisible, inaudible, but no less dangerous threat generated by the "kernel community". It is this space one has to enter in order to interact with the community.

Linux Kernel development has since adopted a code of conduct "in the interest of fostering an open and welcoming environment"13 and Linus Torvalds has taken "time off [to] get some assistance on how to understand people's emotions and respond appropriately". ${ }^{14}$

Controversies such as these often attract media attention. Because participants anticipate their communication being under constant observation by a mass audience, the atmosphere on the LKML becomes a pressing topic for field-internal reflection. A phenomenology of the lived body sharpens our analytical awareness of the fact that such projects are not only about "rough consensus and running code", as is suggested by participants' own descriptions of them, but also about their embodied experience and the structure of the social resonance space, within which LKMLcommunications are performed. The presence of others on the spatially experienced mailing list can be experienced as hurtful but also as motivating and encouraging. As we have shown, interaction analysis expanded to include the concepts of a phenomenology of the lived body and the social resonance space can provide a more nuanced description of these phenomena.

\section{Conclusion}

In this article we show in which way the concept of interaction as it is used in the tradition of Goffman and Luhmann leads to an understanding of digital communication that describes this emerging form of technically mediated interaction as less real (Lombard and Ditton 1997) or even a pathological (Turkle 2011) form of interaction respectively communication. Even studies, which focus on the concrete experience of presence in technically mediated communications, primarily highlight the temporal aspect of presence (e.g., Hardesty/Sheredos 2019, Knorr Cetina 2009: 79, Zhao 2015). Thus they fail to take into account the particular spatiality of these interactions. Presence is understood only as a temporal but not as a spatio-temporal phenomenon. While Friesen (2014) and Berger (2020) both consider the embodied experience of space to some extent, they do not succed in giving a detailed analysis of spatial experience.

To avoid these conceptual shortcomings we suggest a new approach based on the phenomenological concepts of the lived body and mediated immediacy (Helmuth Plessner) combined with the concepts of embodied space (Hermann Schmitz).

\footnotetext{
13 https://github.com/torvalds/linux/commit/8a104f8b5867.

14 https://lkml.org/lkml/2018/9/16/167.
} 
Herewith we avoid a restricted understanding of interaction that does not allow for an appropriate empirical analysis of the emerging structures of digital communication.

With respect to an analysis of interactions in an open source project, we provide a principle proof of the empirical significance of our proposed conceptual framework. In open-source projects, Internet-based communication technologies are used in a routine way and accepted as a natural part of this activity. Although participants rarely meet each other face to face, they nevertheless experience their communication as an encounter with others in a shared space. This space is established in particular by text-based communicative gestures.

At present such spaces of interaction permeate everyday life and all relationships, whether it be with colleagues, friends, or closest family members. Face-to-face interaction and electronically mediated communication seamlessly blend in everyday life. In many cases, such as in the field of open-source software development, real names are used, or those involved know the real names behind the pseudonyms. Therefore we need analytical concepts, which allow for describing the experience of different spatial relations, without denying reality to some of these experiences.

Schmitz distinguishes between different forms of spatial experience, with the space of vastness figuring as the basic form of spatial experience. We interpret this space as a basic social resonance space. It encompasses face-to-face interactions as well as those that are technologically mediated. As a second form of spatial experience we identify directional space, in which lived bodies direct themselves at one another and affect one another immediately either in a symbolically or both symbolically and technically mediated way. Local space, the third form of spatial experience, is the form of space sociological interaction theories (Goffman, Luhmann) usually refer to.

Conceptualizing these forms of spatial experience allows us to describe the similarities and differences between face-to-face interaction and technologically mediated interaction. Both of these occur in social resonance space, which is always at least implicitly present. Until recently, participants in face-to-face interactions thought of these as only being able to occur in local space. Social resonance space was only implicitly or quite rarely of practical relevance, such as when someone directs him/herself at me from somewhere else-in a letter or a landline phone call. But if interactions are mediated in a more technologically comprehensive way, social resonance space is experienced directly as a space of vastness. It is always possible that others will direct themselves at me in a technologically mediated way-with a message on a computer or a smartphone. By structuring interaction in this way, social resonance space becomes practically relevant.

Of course these spaces cannot be isolated against each other. Even if the social resonance space of face-to-face interaction is experienced practically as a local space, it is specified as such from a background of a space of vastness, from which other actors can intrude a particular local space. For example, I talk to my friend in a bar, and my mobile indicates a message. Someone from somewhere has addressed me. If the focus is on internet-based communication (see the analysis of the mailing list communication above) the social resonance space is specified as a space of vastness. Nevertheless, entering this particular social resonance space is also related to a particular local space, where an embodied self sits in front of computer display. 
Using the proposed concepts, we are not forced to distort the phenomenon of concrete experience, instead we can analyze how concrete actors make sense of their spatial experiences, without denying reality to some of them.

This approach not only makes it possible to analyze the emerging digital culture, but also allows sociology to abandon its methodological ethnocentrism. In the ethnological research we find numerous examples of interactions with actors (such as ghosts or deceased ancestors) that cannot meaningfully be situated in three-dimensionally extended local space, but can indeed be situated in an experiential space without a local-space structure. Limiting the definition of interaction to actors present in local space is based on a historically contingent state of affairs that is on the verge of changing. We have shown that mediatized communication seems to exhibit structures similar to those identified in ethnological research: other actors are experienced as existing in unstructured, i.e., non-measurably extended space. They are experienced as being present somewhere in the surrounding space without being situated in a measurably extended place.

In short, we suggest a revision of basic premises of interaction analyses. First, we understand space not only as a shared local space, instead we propose a broadened understanding of space, which includes the space of vastness and embodied directional space. Second, this allows for an understanding of presence, which is not only understood as a temporal, but always as a spatio-temporal phenomenon. Third we propose a new understanding of actors as lived bodies, which relate in a mediated immediate way to their environment. These lived bodies are "artificial by nature" (Plessner 1928/2019: 309ff.) that is, there is no true nature of embodied selves, instead their immediate experience is always mediated by technology and symbols. Fourth, we introduce the concept of digital space. This allows us to grasp the space of technological functioning and to understand how it differs from the space of embodied experience. Using these concepts of embodied selves and embodied space makes it possible for sociological analysis not only to abandon its methodological ethnocentrism, but also prepares it for the challenge of analyzing the emerging forms of digital culture.

Funding Open Access funding enabled and organized by Projekt DEAL.

Open Access This article is licensed under a Creative Commons Attribution 4.0 International License, which permits use, sharing, adaptation, distribution and reproduction in any medium or format, as long as you give appropriate credit to the original author(s) and the source, provide a link to the Creative Commons licence, and indicate if changes were made. The images or other third party material in this article are included in the article's Creative Commons licence, unless indicated otherwise in a credit line to the material. If material is not included in the article's Creative Commons licence and your intended use is not permitted by statutory regulation or exceeds the permitted use, you will need to obtain permission directly from the copyright holder. To view a copy of this licence, visit http://creativecommons.org/licen ses/by/4.0/. 


\section{References}

Ayaß, R. (2014). Media structures of the Life-world. In M. Staudigl \& G. Berguno (Eds.), Schutzian phenomenology and Hermeneutic Traditions (pp. 93-110). Dordrecht: Springer.

Bachmann-Medick, D. (2016). Spatial turn. Cultural turns: New orientations in the study of Culture (pp. 211-243). Berlin/Boston: De Gruyter.

Bracken, C. C., \& Skalski, P. (Eds.). (2010). Immersed in media. Telepresence in everyday Life. New York: Routledge.

Dickel, S. (2013). Im Netz der Selbstreferenz: Facebook-Kommunikation als Reaktion auf die Katastrophe des Internet. In U. Dolata \& J.-F. Schrape (Eds.), Internet, Mobile Devices und die Transformation der Medien. Radikaler Wandel als schrittweise Rekonfiguration (pp. 331-356). Berlin: edition sigma.

Esposito, E. (1995). Interaktion, Interaktivität und die Personalisierung der Massenmedien. Soziale Systeme, 2, 225-260.

Friesen, N. (2014). Telepresence and Tele-absence. A phenomenology of the (in)visible Alien online. Phenomenology and Practice, 8, 17-31.

Fritz-Hoffmann, C. (2017). Grundzüge eines erweiterten Berührungsbegriffs. Soziale Welt, 68(2-3), 199-224.

Gardner, P., \& Jenkins, B. (2015). Bodily Intra-actions with Biometric devices. Body and Society, 22(1), 3-30.

Goffman, E. (1959). The presentation of self in everyday Life. New York: Doubleday Anchor Original.

Goffman, E. (1963). Behavior in public places. Notes on the social organization of gatherings. New York: The Free Press.

Goffman, E. (1964). The neglected situation. American Anthropologist_PART2, 66(6), 133-136.

Goffman, E. (1967). On face-work an analysis of ritual elements in social interaction. In E. Goffman, Interaction ritual Ders (pp. 5-45). New York: Doubleday.

Goffman, E. (1981a). Footing. In E. Goffman, Forms of talk (pp. 124-159). Oxford: Basil Blackwell.

Goffman, E. (1981b). Response cries. In E. Goffman, Forms of talk (pp. 78-123). Oxford: Basil Blackwell.

Goffman, E. (1983a). Felicity's condition. American Journal of Sociology, 89(1), 1-53.

Goffman, E. (1983b). The interaction order. American Sociological Association, 1982 Presidential Address. American Sociological Review, 48(1), 1-17.

Goffman, E. (2000). Relations in public microstudies of the public order. New Brunswick (USA)/London (UK): Transaction Publishers.

Gugutzer, R. (2012). Verkörperungen des Sozialen. Neophänomenologische Grundlagen und Soziologische Analysen. Bielefeld: Transcript.

Habermas, J. (2003). Hermeneutic and analytic philosophy: Two complementary versions of the linguistic turn. In J. Habermas, Truth and justification (pp. 51-82). Cambridge: Trans Barbara Fultner Polity.

Hahn, C., \& Stempfhuber, M. (2015). Präsenzen 2.0. Körperinszenierungen in Medienkulturen. Wiesbaden: Springer VS.

Hardesty, R. A., \& Sheredos, B. (2019). Being together, worlds apart: A virtual-worldly phenomenology. Human Studies, 42(3), 343-370.

Kieserling, A. (1999). Kommunikation unter Anwesenden. Studien über Interaktionssysteme (1st ed.). Frankfurt am Main: Suhrkamp.

Klemm, M., \& Staples, R. (2015). Warten auf Antwort. Digitale Kommunikation im Spannungsfeld Körperlicher und textueller Selbstrepräsentation. In C. Hahn, \& M. Stempfhuber (Eds.), Martin Stempfhuber Präsenzen 2.0 Körperinszenierungen in Medienkulturen (pp. 113-134). Wiesbaden: Springer VS.

Knorr-Cetina, K. (2009). The synthetic situation: Interactionism for a global world. Symbolic Interaction, 32(1), 61-87.

Krotz, F., Despotović, C., \& Kruse, M.-M. (Eds.). (2014). Die Mediatisierung sozialer Welten. Synergien empirischer Forschung. Wiesbaden: Springer VS.

Krotz, F., \& Hepp, A. (Eds.). (2012). Mediatisierte Welten. Wiesbaden: VS Verlag für Sozialwissenschaften.

Kwan, M. L. (2004). Presence, Explicated. Communication Theory, 14(1), 27-50. 
Leenhardt, M. (1947/1979). Do kamo: Person and Myth in the Melanesian world (B.M. Gulati, Rrans). Chicago \& London: The University of Chicago Press.

Licoppe, C. (2004). "Connected" presence: The emergence of a new repertoire for managing social relationships in a changing communication technoscape. Environment and Planning D, 22(1), 135-156.

Licoppe, C. (2015). Contested norms of presence. In C. M. Hahn \& Stempfhuber (Eds.), Präsenzen 2.0. Körperinszenierungen in Medienkulturen (pp. 97-112). Wiesbaden: Springer VS.

Licoppe, C., \& Morel, J. (2016). Proximity awareness and the privatization of sexual encounters with strangers the case of grindr. In C. Marvin, S. H. Hong, \& B. Zelizer (Eds.), Context Collapse: Reassembling the spatial. London: Routledge.

Lindemann, G. (2008). Theoriekonstruktion und empirische Forschung. In H. Kalthoff, S. Hirschauer, \& G. Lindemann (Eds.), Theoretische Empirie. Zur Relevanz qualitativer Forschung (pp. 107-128). Frankfurt/M.: Suhrkamp.

Lindemann, G. (2010). The living human body From the perspective of the shared world (Mitwelt). Journal of Speculative Philosophy, 24(3), 275-291.

Lindemann, G. (2020). Approaches to the world. The multiple dimensions of the social. Baden-Baden: Nomos (in press).

Lombard, M., \& Ditton, T. (1997). At the heart of it all: The concept of presence, In: Journal of Computer-Mediated Communication, 3(2). Im Internet: URL: http://onlinelibrary.wiley.com/enhanced/ doi/https://doi.org/10.1111/j.1083-6101.1997.tb00072.x/, retrieved August 262014.

Löw, M. (2016). The sociology of space: Materiality, social structures, and action. New York: Palgrave Macmillan.

Luckmann, T. (1970). The boundaries of the social world. In M. Natanson (Ed.), Phenomenology and social reality. Essays in Memory of Alfred Schütz (pp. 73-100). The Hague: Nijhoff.

Luhmann, N. (1995). Social systems (J. Bednarz, Jr \& D. Baecker, Trans.). Stanford, CA: Stanford University Press.

Luhmann, N. (2013). Theory of society (R. Barrett, Trans.). Stanford, CA: Stanford University Press.

Mehler, A. (2010). Artifizielle Interaktivität. Eine semiotische Betrachtung. In T. Sutter, \& A. Mehler (Eds.), Medienwandel als Wandel von Interaktionsformen (pp. 107-134). Wiesbaden: VS Verlag.

Merleau-Ponty, M. (1945/2014). Phenomenology of Perception. London: Routledge.

Ollinaho, O. I. (2018). Virtualization of the life-world. Human Studies, 41, 193-209.

Panofsky, E. (1927/1991). Perspective as symbolic form (Ch. S. Wood, Trans.). New York: Zone Books.

Plessner, H. (1928/2019). The levels of the organic and the human, An introduction to philosophical anthropology (Millay Hyatt, Trans.). Fordham University Press.

Rettie, R. (2009). Mobile phone communication: Extending goffman to mediated interaction. Sociology, 43(3), 421-438.

Rosa, H. (2016). Resonance. A sociology of our relationship to the world. Cambridge, Oxford, Boston, New York: Polity.

Schmitz, H. (1967). System der Philosophie leibliche Raum. Bonn: H Bouvier u Co.

Schroer, M. (2006). Räume, Orte, Grenzen: Auf dem Weg zu einer Soziologie des Raums. Frankfurt/Main: Suhrkamp.

Schütz, A., \& Luckmann, T. (1973). The Structures of the life-world (R. M. Zaner, Trans.). Evanston: Northwestern University Press.

Smith, G. W. H. (2006). Enacted others: Specifying Goffman's phenomenological omissions and sociological accomplishments. Human Studies, 2006(28), 397-415.

Srubar, I. (1979). Die Theorie der Typenbildung bei Alfred Schütz: Ihre Bedeutung und ihre Grenzen. In W. M. Sprondel \& R. Grathoff (Eds.), Alfred Schütz und die Idee des Alltags in den Sozialwissenschaften (pp. 43-64). Stuttgart: Ferdinand Enke Verlag.

Sutter, T. (2010). Der Wandel von der Massenkommunikation zur Interaktivität neuer Medien. In T. Sutter \& A. Mehler (Eds.), Medienwandel als Wandel von Interaktionsformen, (pp. 83-105). Wiesbaden: VS Verlag, $\mathrm{S}$.

Sutter, T., \& Charlton, M. (Eds.). (2001). Massenkommunikation, Interaktion und soziales Handeln (1st ed.). Wiesbaden: Westdt. Verl.

Sutter, T., \& Mehler, A. (Eds.). (2010). Medienwandel als Wandel von Interaktionsformen. Wiesbaden: VS Verlag.

Tipp, A. (2008). Doing being present. Instant messaging aus interaktionssoziologischer Perspektive. In Ch. Stegbauer, \& M. Jäckel (Eds.), Social Software. Formen der Kooperation in computerbasierten Netzwerken (pp. 175-194). Wiesbaden: VS Verlag, S. 
Turkle, S. (2011). Alone together: Why we expect more from technology and less from each other. New York: Basic Books.

Ullrich, C. G., \& Schiek, D. (2015). Forumsdiskussionen im Internet als reaktives Instrument der Datenerhebung. Ein Werkstattbericht. In D. Schirmer, N. Sander, \& A. Wenninger (Eds.), Die qualitative Analyse internetbasierter Daten. Methodische Herausforderungen und Potenziale von OnlineMedien (pp. 133-160). Wiesbaden: Springer VS (Soziologische Entdeckungen).

van Doorn, N. (2011). Digital spaces, material traces: How matter comes to matter in online performances of gender, sexuality and embodiment. Media, Culture and Society, 33(4), 531-547.

Wehner, J. (1997). Interaktive Medien - Ende der Massenkommunikation? Zeitschrift für Soziologie, $26(2), 96-114$.

Werron, T. (2015). Gleichzeitigkeit unter Abwesenden: Zu Globalisierungseffekten elektrischer Kommunikationstechnologien. In: Heintz, Bettina, Hartmann Tyrell, (Ed.) Interaktion - Organisation Gesellschaft revisited. Anwendungen, Erweiterungen, Alternativen. (pp. 251-270). Sonderheft der Zeitschrift für Soziologie. Lucius and Lucius: Stuttgart.

Westerman, D., \& Skalski, P. (2010). Computers and telepresence: A ghost in the machine? In C. C. Bracken \& P. Skalski (Eds.), Immersed in media (pp. 63-86). New York: Telepresence in Everyday Life Routledge.

Zhao, S. (2015). Constitution of mutual knowledge in telecopresence. Updating Schutz's phenomenological theory of the lifeworld. Journal of Creative Communications, 10(2), 105-127.

Publisher's Note Springer Nature remains neutral with regard to jurisdictional claims in published maps and institutional affiliations. 